CARDIOVASCULAR MEDICINE

\title{
Value of echocardiography for diagnosis and prognosis of chronic Chagas disease cardiomyopathy without heart failure
}

\author{
R J Viotti, C Vigliano, S Laucella, B Lococo, M Petti, G Bertocchi, B Ruiz Vera, H Armenti
}

Heart 2004;90:655-660. doi: 10.1136/hrt.2003.018960

See end of article for authors' affiliations

Correspondence to: Dr Rodolfo J Viotti, José Hernández 4181, Villa Ballester, 1653, Argentina; peron@ millicom.com.ar

Accepted 20 October 2003
Objectives: To establish the usefulness of echocardiography for the clinical classification of patients with Chagas disease and to determine the predictors of mortality and clinical events.

Methods: 849 patients with chronic Chagas disease with a mean follow up of 9.9 years were studied. On admission, ECG, chest radiograph, and two dimensional echocardiogram were obtained from all patients. Clinical events were defined as new ECG abnormalities, change in clinical status resulting in transfer to another group, and death. Morphologically characterised segmental lesions were also seen in 12 patients on a second harmonic echocardiogram with intravenous contrast agent. Univariate and multivariate analysis for clinical events and mortality were performed.

Setting: Community of San Martín, Buenos Aires, Argentina.

Results: Change in clinical group (68 of 833 survivors $v 15$ of 16 who died, $p<0.001$ ), left ventricular systolic dimension (mean (SD) $3.06(0.72) \mathrm{cm} \vee 4.71(0.90) \mathrm{cm}, \mathrm{p}<0.0001$ ), and ejection fraction (mean (SD) $0.67(0.11) \% \vee 0.42(0.17) \%, \mathrm{p}<0.0001)$ were found to be the only predictors of mortality. ECG abnormalities related to the disease (in 220 of 699 patients with no clinical event $v 98$ of 150 patients with a clinical event, $\mathrm{p}<0.0001$ ), left ventricular diastolic dimension (mean (SD) $4.88(0.54) \mathrm{cm} v 5.44$ $(0.83) \mathrm{cm}, \mathrm{p}<0.0001$ ), left ventricular systolic dimension (mean (SD) $2.98(0.62) \mathrm{cm} v 3.64(1.03) \mathrm{cm}$, $\mathrm{p}<0.0001$ ), and ejection fraction (mean (SD) $0.68(0.10) \% \vee 0.60(0.16) \%, p<0.0001$ ) were predictors of clinical events. Segmental lesions were observed in 211 of 849 patients (25\%). Segmental lesions were seen in $66(13 \%)$ and systolic dysfunction was seen in four of $505(0.8 \%)$ patients with normal ECG. Significant differences were found between the groups of patients (group 0: reactive serology and normal ECG and chest radiography without cardiac enlargement and no signs of heart failure; group 1: reactive serology and abnormal ECG and chest radiography without cardiac enlargement; group 2: reactive serology and abnormal ECG and chest radiography with cardiac enlargement and no signs of heart failure).

Conclusion: Echocardiography was useful both to characterise and to determine the prognosis of patients with chronic Chagas disease without heart failure.

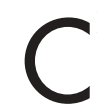
hagas disease is the main cause of infectious myocarditis, ${ }^{1}$ affecting about $25 \%$ of the $15-20$ million Latin Americans who are infected. ${ }^{2}$ Infection with Trypanosoma cruzi exhibits both an acute and a chronic phase, separated by an indeterminate period, in which the patient is relatively asymptomatic. ${ }^{3}$ However, even when the asymptomatic period lasts 10-30 years, infected patients may develop signs and symptoms of chronic Chagas disease. Various factors have been reported to contribute to the progressive heart damage of Chagas disease, ${ }^{4}$ such as the aetiological agent or antigenic components of the parasite in cardiac tissue $^{56}$ and an abnormal immune response that fails to control the infection..$^{78}$ These lead to cellular damage and diffuse or focal chronic myocarditis, with evolution to fibrosis. ${ }^{9}$

The main feature of chronic Chagas disease is the development of cardiomyopathy, which is usually observed in adults who were infected in childhood. ${ }^{10}$ The polymorphism of the clinical manifestations ${ }^{11}$ can be summarised as follows: intraventricular conduction system abnormalities, ventricular arrhythmia, sinus node dysfunction, left ventricular segmental lesions, and enlargement and dysfunction of left ventricle with or without heart failure. The main causes of death are heart failure and sudden death (about $70 \%$ and $30 \%$, respectively). ${ }^{12}$
Echocardiography is a useful complementary method for the follow up of patients with chronic Chagas disease myocarditis; however, echocardiograms are not part of the clinical classification of patients with chronic Chagas disease. ${ }^{13}{ }^{14}$ Moreover, few studies involving large numbers of patients have been carried out to establish the prognostic value of the echocardiographic variables for the evolution of cardiomyopathy or death. Most of the studies examined patients with heart failure or advanced heart disease. ${ }^{15-17}$ Similarly, few reports analysed the type, location, and differences between segmental lesions. ${ }^{18-20}$ Our objectives were both to establish the diagnostic and prognostic value of echocardiography in chronic Chagas disease without heart failure and to characterise the location and morphology of segmental lesions.

\section{METHODS}

\section{Patients}

Eight hundred and forty nine patients with chronic Chagas disease were enrolled at Hospital Eva Perón, San Martín, Buenos Aires, Argentina. The presence of $T$ cruzi antibodies was tested by an enzyme linked immunosorbent assay (ELISA), indirect haemagglutination, and indirect immunofluorescence assays. A patient was considered to be infected when at least two of the tests were positive. ${ }^{21}$ Patients with 

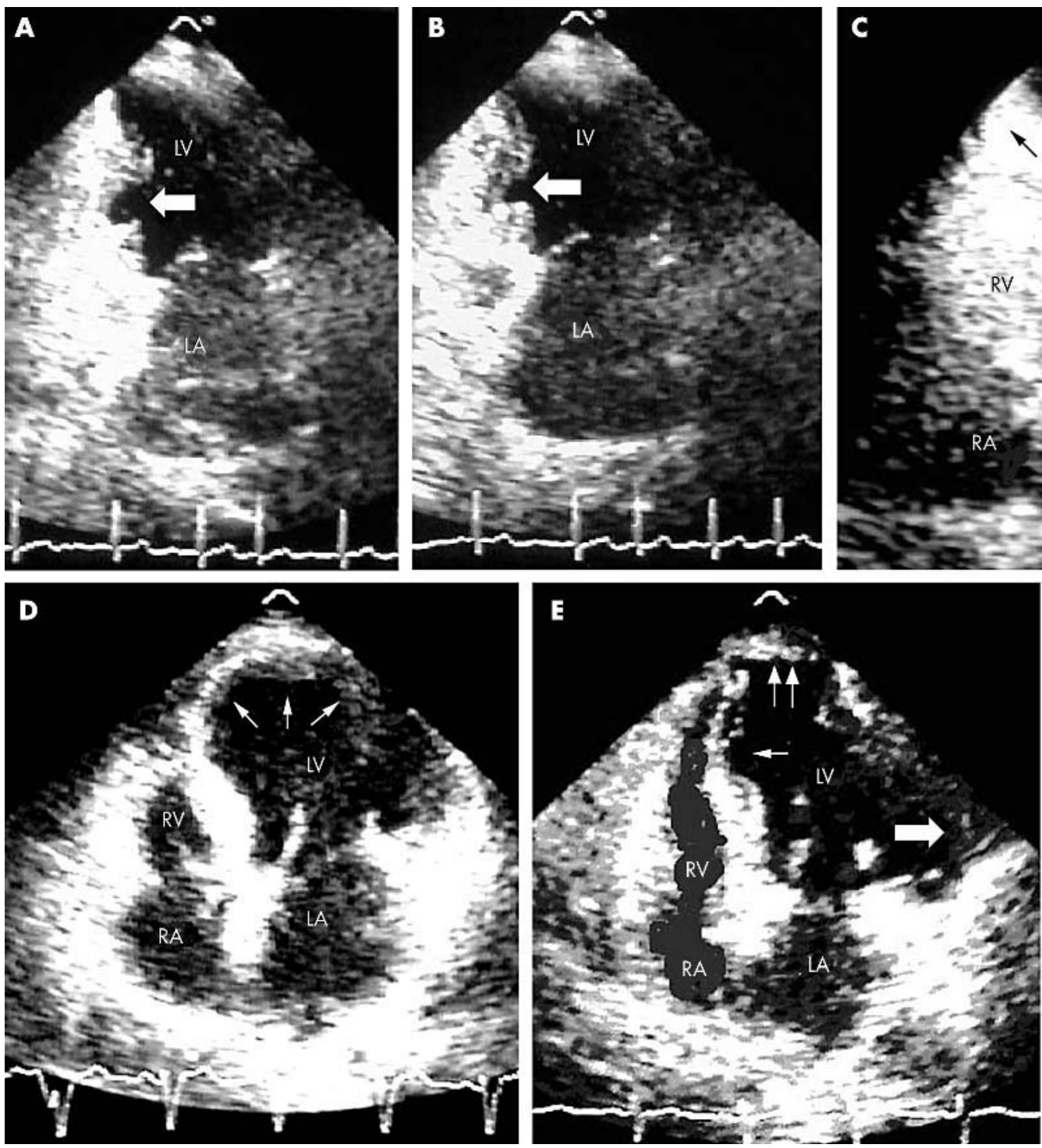

Figure 1 (A) Two chamber apical view from in a 67 year old female patient showing hollow punch lesion type I (arrow) without left ventricular (LV) dilatation or systolic dysfunction in the mid inferior wall during diastole. LA, left atrium. (B) The same patient during systole. (C) Four chamber apical view with intravenous contrast agent showing apical hernia with thrombus (Th), LV dilatation, and normal systolic function in a 44 year old female patient. The wall of the hernia has no muscular layer (arrows). RA, right atrium; RV, right ventricle. (D) Four chamber apical view with extensive thinning of apical segments (arrows), LV enlargement, and systolic dysfunction in a 60 year old male patient. (E) Four chamber apical view with all three kinds of segmental lesions, LV enlargement, and systolic dysfunction in a 71 year old female patient. Small arrow, type I lesion in the interventricular septum; double arrow, type II lesion on apical segments; large arrow, type III lesion on the lateral wall.

congenital, hypertensive, coronary, alcoholic, or other associated cardiomyopathies were excluded from this study. ECG, stress testing, chest radiography, and two dimensional echocardiography were performed on admission in all patients with confirmed positive serology for T cruzi.

Patients were classified into clinical groups according to Kuschnir ${ }^{22}$ : group 0, reactive serology and normal ECG and chest radiography without cardiac enlargement; group 1 , reactive serology and abnormal ECG and chest radiography without cardiac enlargement; and group 2, reactive serology and abnormal ECG and chest radiography with cardiac enlargement and neither radiological nor clinical signs of heart failure. Group 3 patients, presenting with heart failure, were excluded because they were considered to be at the end stage of the disease and therefore to have a high expected mortality.

During follow up, complete right bundle branch block, left anterior fascicular block, complete left bundle branch block, ventricular premature complexes of Lown degree II or greater, electrical inactivation areas, atrial flutter, atrial fibrillation, atrial tachycardia, sinus bradycardia $<50$ beats/ min, sustained and non-sustained ventricular tachycardia, second degree type II atrioventricular block, complete atrioventricular block, and placement of pacemakers ${ }^{21}$ were considered either previous ECG abnormalities related to the disease or new ECG abnormalities related to the disease. Once divided into clinical groups, patients were periodically evaluated as follows: group 0, ECG every six months to one year; group 1, ECG every four months; and group 2, ECG every three months. Holter monitoring or repeated stress testing and echocardiogram were optional for groups 0 and 1 , according to symptoms or to the observation of new ECG abnormalities related to the disease and otherwise done every five years. Chest radiographs were taken of all the patients every year. Echocardiograms were performed every two years. Holter monitoring and stress testing were optional for patients belonging to group 2 . 
Table 1 Univariate analysis for mortality and clinical events in patients with chronic Chagas disease

\begin{tabular}{|c|c|c|c|c|c|}
\hline Variable & Survival & Death & No clinical event & Clinical event & Total \\
\hline Age at admission (years) & $43.39(11.11)$ & $49.12(13.11)^{* *}$ & $42.65(11.21)$ & 47.50 (10.13)†† & 849 \\
\hline EARD & $304 / 833$ (36\%) & $14 / 16(87 \%)^{* * *}$ & $220 / 699(31 \%)$ & $98 / 150(65 \%) \dagger \dagger$ & 849 \\
\hline NEARD & $112 / 833(13 \%)$ & $9 / 16(56 \%)^{* * *}$ & - & - & 849 \\
\hline Change in clinical group & $68 / 833(8 \%)$ & $15 / 16(94 \%)^{* * *}$ & - & - & 849 \\
\hline $\operatorname{RVDD}(\mathrm{cm})$ & $1.85(0.55)$ & $2.12(0.55)$ & $1.83(0.52)$ & $1.97(0.65) \dagger$ & 753 \\
\hline LVDD $(\mathrm{cm})$ & $4.96(0.62)$ & $5.99(0.68)^{\star * *}$ & $4.88(0.54)$ & $5.44(0.83) \dagger \dagger$ & 849 \\
\hline LVSD $(\mathrm{cm})$ & $3.06(0.72)$ & $4.71(0.90)^{\star * *}$ & $2.98(0.62)$ & $3.64(1.03)+\dagger$ & 840 \\
\hline LASD $(\mathrm{cm})$ & $3.44(0.57)$ & $3.82(0.82)$ & $3.39(0.54)$ & $3.74(0.69)+\dagger$ & 817 \\
\hline Radius: thickness ratio & $2.88(0.70)$ & $3.97(1.50)^{*}$ & $2.83(0.65)$ & $3.24(1.02) \dagger \dagger$ & 823 \\
\hline PWT $(\mathrm{cm})$ & $0.89(0.22)$ & $0.81(0.18)$ & $0.89(0.21)$ & $0.89(0.27)$ & 825 \\
\hline SWT $\mathrm{cm})$ & $0.98(0.24)$ & $0.95(0.20)$ & $0.98(0.23)$ & $0.99(0.27)$ & 820 \\
\hline Systolic dysfunction & $60 / 832(7 \%)$ & $8 / 16(50 \%)^{* * *}$ & $30 / 698(4 \%)$ & $38 / 150(25 \%) \dagger \dagger$ & 848 \\
\hline Segmental lesions & $197 / 833(24 \%)$ & $14 / 16(87 \%)^{* * *}$ & $141 / 699(20 \%)$ & $70 / 150(47 \%)+\dagger$ & 849 \\
\hline $\mathrm{EF}(\%)$ & $0.67(0.11)$ & $0.42(0.17)^{\star * *}$ & $0.68(0.10)$ & $0.60(0.16) t \dagger$ & 840 \\
\hline
\end{tabular}

Data are mean (SD) or proportion.

Evaluation by $\chi^{2}$ test: clinical events, change in clinical group, EARD (ECG abnormalities related to the disease), NEARD (new ECG abnormalities related to the disease), systolic dysfunction, and segmental lesions. Evaluated by unpaired Student's $t$ test: LASD (left atrial systolic dimension), LVDD (left ventricular diastolic dimension), LVSD (left ventricular systolic dimension), PWT (diastolic posterior wall thickness), RVDD (right ventricular diastolic dimension), and SWT (diastolic septal wall thickness).

${ }^{*} \mathrm{p}<0.01 ;{ }^{* *} \mathrm{p}<0.05 ;{ }^{* * *} \mathrm{p}<0.0001$ compared with alive group; $\mathrm{tp}<0.05 ; \mathrm{t} \mathrm{p}<0.0001$ compared with patients without clinical events.

A Toshiba SSH 140 A ultrasound (Toshiba, Tokyo, Japan) and 2.5-3.7 MHz transducers were used to run the echocardiograms.

\section{Prognostic variables}

Age on admission, years of follow up, presence of either ECG abnormalities related to the disease or new ECG abnormalities related to the disease, change in clinical status resulting in transfer to another group, right ventricular diastolic dimension, left ventricular diastolic and systolic dimensions, left atrial systolic dimension, diastolic posterior wall thickness, diastolic septal wall thickness, radius to thickness ratio, left ventricular systolic dysfunction (as reported by the physician), ejection fraction (Teichholz), and the presence of segmental lesions were analysed to study mortality and clinical events. These variables were also used to compare the clinical groups on admission. New ECG abnormalities related to the disease, change in clinical group, and death were defined as clinical events, taking into account only one per patient. New onset heart failure was considered to be a clinical event that was included in the variable change in clinical group. Only cardiac death was taken into account, without distinguishing the mechanisms of cardiac arrest (heart failure, sudden death, and thromboembolic events).

\section{Type and location of segmental lesions}

The types of regional contraction abnormality, as established by the American Society of Echocardiography, ${ }^{23}$ were defined as hypokinesis, akinesis, dyskinesis, and aneurysmal. Segmental lesions found in the apical, posterior, inferior, anterior, lateral, and septal cardiac walls were recorded. To improve the identification of morphological differences between segmental lesions, 12 patients were selected for further analysis by two dimensional echocardiography (ATL 3000 with $2.5 \mathrm{MHz}$ transducer) with a second harmonic and contrast agent (4 g of intravenous contrast agent (Levovist NR) administered over a 10 minute period).

\section{Statistical analysis}

A univariate analysis was performed to determine differences in mortality and clinical events. Student's $t$ test was applied for continuous variables and $\chi^{2}$ test for categorical variables. Only variables shown to be statistically different in the univariate analysis were used in the multivariate analysis with logistic regression. For the analysis of logistic regression of mortality, ejection fraction was considered an offset variable because of its well known prognostic value for mortality and its colinearity with left ventricular systolic dimension. To compare continuous variables (described above under "Prognostic variables") between clinical groups,

Table 2 Multivariate analysis for mortality and clinical events in patients with chronic Chagas disease

\begin{tabular}{|c|c|c|c|c|}
\hline \multirow[b]{2}{*}{ Variable } & \multicolumn{2}{|l|}{ Mortality } & \multicolumn{2}{|c|}{ Clinical events } \\
\hline & $\beta$ Coefficient & p Value & $\beta$ Coefficient & p Value \\
\hline Age at admission & -0.00895 & 0,81 & 0.01 & 0.18 \\
\hline EARD & 1.4 & 0.11 & 0.73 & $0.003^{*}$ \\
\hline NEARD & 0.51 & 0.55 & - & - \\
\hline Change in clinical group & 2.31 & $0.0068^{*}$ & - & - \\
\hline LVDD & -1.46 & 0.08 & 3.05 & $0.003^{*}$ \\
\hline LVSD & 2.33 & $0.001^{*}$ & -3.61 & $0.02^{*}$ \\
\hline RVDD & - & - & 0.06 & 0.78 \\
\hline LASD & - & - & 0.32 & 0.12 \\
\hline Systolic dysfunction & -1.02 & 0.29 & 0.46 & 0.28 \\
\hline Segmental lesions & 1.02 & 0.29 & 0.15 & 0.59 \\
\hline Radius: thickness & 0.47 & 0.22 & 0.33 & 0.07 \\
\hline EF† & $-7.38^{*} \ddagger$ & $0.003^{*} \ddagger$ & -14.78 & $0.01^{*}$ \\
\hline
\end{tabular}


Table 3 Type and location of segmental lesions

\begin{tabular}{lllll}
\hline \multirow{5}{*}{$\begin{array}{l}\text { Type of segmental lesion (number of segmental lesions per wall/total segmental } \\
\text { lesions of each type) }\end{array}$} \\
\cline { 2 - 5 } Location & $\begin{array}{l}\text { Hypokinesis } \\
\text { (105 patients) }\end{array}$ & $\begin{array}{l}\text { Akinesis } \\
\text { (20 patients) }\end{array}$ & $\begin{array}{l}\text { Dyskinesis } \\
\text { (14 patients) }\end{array}$ & $\begin{array}{l}\text { Aneurysms } \\
\text { (73 patients) }\end{array}$ \\
\hline Apical wall & $71 / 126(56 \%)$ & $12 / 32(37 \%)$ & $12 / 20(60 \%)$ & $52 / 105(49 \%)$ \\
Posterior wall & $23 / 126(18 \%)$ & $10 / 32(31 \%)$ & $2 / 20(10 \%)$ & $26 / 105(25 \%)$ \\
Inferior wall & $8 / 126(6 \%)$ & $8 / 32(25 \%)$ & $2 / 20(10 \%)$ & $13 / 105(12 \%)$ \\
Anterior wall & $1 / 126(0.8 \%)$ & $0 / 32(0 \%)$ & $0 / 20(0 \%)$ & $2 / 105(2 \%)$ \\
Lateral wall & $4 / 126(3 \%)$ & $0 / 32(0 \%)$ & $0 / 20(0 \%)$ & $4 / 105(4 \%)$ \\
Interventricular septum & $19 / 126(15 \%)$ & $2 / 32(6 \%)$ & $4 / 20(20 \%)$ & $8 / 105(8 \%)$ \\
Total segmental lesions & 126 & 32 & 20 & 105 \\
\hline
\end{tabular}

a one way analysis of variance followed by a Scheffé test was carried out, $\mathrm{p}<0.05$ being considered significant. Data were analysed by Statistix 7.0 analytical software.

\section{RESULTS}

\section{Prognostic variables in chronic Chagas disease}

We evaluated 849 patients with chronic Chagas disease (333 men and 516 women) with a mean (SD) age of 43.5 (11.1) years (range 18-74 years) and with a mean (SD) follow up of 9.9 (5.3) years (range 2-23 years). Table 1 shows the univariate analysis for mortality and clinical events. All variables except posterior wall and interventricular septum thickness (considered for the comparison between the alive and the dead groups, as well as between patients with and those without clinical events) were significantly different. Change in clinical group, left ventricular systolic dimension, and ejection fraction were the only independent predictors of mortality. ECG abnormalities related to the disease, left ventricular diastolic dimension, left ventricular systolic dimension, and ejection fraction were predictors of clinical events (table 2 ).

\section{Type and location of segmental lesions}

As table 3 shows, segmental lesions were observed mainly in the apical and posterior walls. The most common lesions were hypokinetic lesions and aneurysms. Only aneurysms

Table 4 Relation between the echocardiogram and the clinical status of patients with chronic Chagas disease grouped by Kuschnir classification

\begin{tabular}{|c|c|c|c|c|}
\hline Variable & $\begin{array}{l}\text { Group } 0 \\
\text { (505 patients) }\end{array}$ & $\begin{array}{l}\text { Group } 1 \\
\text { (257 patients) }\end{array}$ & $\begin{array}{l}\text { Group } 2 \\
\text { (87 patients) }\end{array}$ & Statistic \\
\hline Age at admission (years) & $40.53(10.9)^{*}$ & $47.18(10.26)$ & $49.93(9.36)$ & $\begin{array}{l}F=51.75 \\
p<0.0001\end{array}$ \\
\hline Follow up (years) & $9.64(5.13)$ & $10.67(5.53) \dagger$ & $9.37(5.49)$ & $\begin{array}{l}F=3.72 \\
p<0.02\end{array}$ \\
\hline NEARD & $33 / 505(6 \%)$ & $55 / 257(21 \%)$ & $33 / 87(38 \%)$ & $\begin{array}{l}\chi^{2}=75.27 \\
p<0.0001\end{array}$ \\
\hline Change in clinical group & $30 / 505(6 \%)$ & $25 / 257(10 \%)$ & $28 / 87(32 \%)$ & $\begin{array}{l}\chi^{2}=57.95 \\
p<0.0001\end{array}$ \\
\hline Mortality & $0 / 505(0 \%)$ & $4 / 257(1 \%)$ & $12 / 87(14 \%)$ & $\begin{array}{l}\chi^{2}=76.57 \\
p<0.0001\end{array}$ \\
\hline Clinical events $\ddagger$ & $39 / 505(8 \%)$ & $66 / 257(26 \%)$ & $45 / 87(52 \%)$ & $\begin{array}{l}\chi^{2}=115.05 \\
p<0.0001\end{array}$ \\
\hline $\operatorname{RVDD}(\mathrm{cm})$ & $1.80(0.48)$ & $1.86(0.56)$ & $2.16(0.75) \S$ & $\begin{array}{l}F=13.83 \\
P<0.0001\end{array}$ \\
\hline LVDD $(\mathrm{cm})$ & $4.81(0.50)$ & $4.98(0.56)$ & $5.94(0.74)$ & $\begin{array}{l}F=155.92 \\
p<0.0005\end{array}$ \\
\hline LVSD $(\mathrm{cm})$ & $2.91(0.54)$ & $3.05(0.66)$ & $4.30(0.97)$ & $\begin{array}{l}F=175,33 \\
p<0.0005\end{array}$ \\
\hline $\operatorname{LASD}(\mathrm{cm})$ & $3.35(0.49)$ & $3.45(0.49)$ & $3.99(0.93) \S$ & $\begin{array}{l}F=45.80 \\
p<0.0001\end{array}$ \\
\hline PWT $(\mathrm{cm})$ & $0.89(0.25)$ & $0.90(0.16)$ & $0.85(0.18)$ & $\begin{array}{l}F=1.81 \\
p<0.16\end{array}$ \\
\hline SWT $(\mathrm{cm})$ & $0.96(0.22)$ & $1.00(0.26)$ & $0.98(0.22)$ & $\begin{array}{l}F=2.16 \\
p<0.11\end{array}$ \\
\hline Radius: thickness ratio & $2.83(0.65)$ & $2.80(0.61)$ & $3.69(1.11) \S$ & $\begin{array}{l}F=53.55 \\
p<0.0001\end{array}$ \\
\hline E point septal separation $\pi(\mathrm{cm})$ & $0.49(0.33)$ & $0.70(0.43)$ & $1.35(0.64)$ & $\begin{array}{l}F=106.77 \\
p<0.0005\end{array}$ \\
\hline Fractional shortening (\%) & $39.36(8.47)$ & $37.57(11.30)$ & $26.65(12.04) \S$ & $\begin{array}{l}F=32.78 \\
p<0.0001\end{array}$ \\
\hline Systolic dysfunction & $4 / 505(0.8 \%)$ & $22 / 257(8 \%)$ & $42 / 87(48 \%)$ & $\begin{array}{l}\chi^{2}=226.93 \\
p<0.0001\end{array}$ \\
\hline Segmental lesions & $66 / 505(13 \%)$ & $84 / 257(33 \%)$ & $61 / 87(70 \%)$ & $\begin{array}{l}\chi^{2}=141.42 \\
p<0.0001\end{array}$ \\
\hline EF (\%) & $0.69(0.09)$ & $0.68(0.11)$ & $0.52(0.16) \S$ & $\begin{array}{l}\chi^{2}=85.12 \\
p<0.0001\end{array}$ \\
\hline
\end{tabular}

*Significantly different from groups 1 and 2; tsignificantly different from groups 0 and 2; łonly one clinical event was considered per patient; §significantly different from groups 0 and 1 , "significant difference between groups 0 , 1 , and 2 . 
were found in the anterior wall; instead, most cases of akinesis were recorded in both the inferior and posterior walls. One hundred and forty seven of 283 segmental lesions were found in the apical wall $(52 \%), 61$ in the posterior wall $(21 \%), 33$ in the interventricular septum wall (12\%), 31 in the inferior wall $(11 \%), 8$ in the lateral wall $(3 \%)$, and 3 in the anterior wall (1\%). Twenty eight of $211(13 \%)$ patients with segmental lesions had lesions involving more than one wall (25 patients with two combined lesions and three with three combined lesions).

Morphological characterisation of segmental lesions Three types of segmental lesions were differentiated by the morphology and extension of the segmental damage: type I, thinning of the wall or "hollow punch" (fig lA, B); type II, apical hernia projecting from the external cardiac edge with normal systolic function (fig $1 \mathrm{C}$ ); and type III, extensive wall thinning, without hernia, similar to myocardial infarction expansion (fig ID). In one patient all three kinds of segmental lesions were observed (fig lE).

\section{Relation between the echocardiogram and the clinical} status of patients with chronic Chagas disease

Table 4 shows the relation between the echocardiographic findings and patients' clinical status according to the Kuschnir classification on admission. Among group 0 patients, $13 \%$ had segmental lesions and $0.8 \%$ had systolic dysfunction.

Significant differences were found in the left ventricular diastolic and systolic dimensions and E point septal separation with reference to groups 0,1 , and 2 , even though in groups 0 and 1 the measurements were within the normal range. All the echocardiographic parameters except diastolic posterior wall thickness and diastolic septal wall thickness were significantly increased in group 2 in comparison with groups 0 and 1 .

\section{DISCUSSION}

The most significant prognostic index of mortality in our study was a change in clinical group. Both left ventricular systolic dimension and ejection fraction were independent predictive values, suggesting that systolic dysfunction may be an important factor in cardiac death. However, systolic dysfunction as reported by the physician did not have a prognostic value probably because this is a qualitative measure. Conversely, left ventricular diastolic dimension, left atrial systolic dimension, radius to thickness ratio, and presence of segmental lesions were not predictors of mortality, as suggested by other authors. ${ }^{17} 2425$ This suggestion was based either on the well known association between left ventricular enlargement, increased diastolic stress, cardiac damage, and death or on the relation between segmental lesions, complex ventricular arrhythmias, and sudden death. ECG abnormalities related to the disease, left ventricular systolic and diastolic dimensions, and ejection fraction were predictors of clinical events. However, left ventricular diastolic dimension and ECG abnormalities related to the disease were not predictors of mortality. This difference between index of mortality and clinical events is unclear. On the one hand, change in clinical group may indicate the unavoidable evolution towards the end phase of the disease and death. This evolution probably is the clinical expression of a chronically active diffuse myocarditis. ${ }^{26}{ }^{27}$ On the other hand, in the less advanced phases of cardiomyopathy, this active myocarditis would be clinically manifested as ECG abnormalities related to the disease or increased left ventricular diastolic dimension. However, as the cardiac damage worsens, the systolic function may be impaired, thus being the main cause of death.
Regarding the segmental lesions, no important differences were found with previous reports showing that segmental lesions are found mainly in the apical and posterior walls, ${ }^{28}$ with hypokinesis and aneurysms being most common. ${ }^{29}{ }^{30}$ It is important to point out that segmental lesions were found in asymptomatic patients with a normal ECG (group 0), suggesting that any person with positive serology for $T$ cruzi should be to considered to have chronic Chagas disease, bearing in mind that pathological findings depend on both the accuracy and sensitivity of the clinical tests used.

In this study, three types of segmental lesions were morphologically defined. To our knowledge, this is the first time that type 1 segmental lesions have been characterised. Echocardiography proved to be a useful complementary test for the clinical classification of chronic Chagas disease and for characterising the type of segmental lesions. Moreover, the echocardiogram may become a good predictor of the outcome of the disease.

\section{Limitations of the study}

Although the aim of our study was evaluating the prognostic value of the most commonly used echocardiographic variables, right ventricular systolic function and diastolic dysfunction would also have been important to analyse. Unfortunately, it was not possible to evaluate these variables because of limitations in economic and technological resources.

The ejection fraction was calculated by the Teichholz method. The usefulness of this method is limited in the presence of segmental lesions.

\section{ACKNOWLEDGEMENTS}

We thank María Gabriela Alvarez for her permanent collaboration, Horacio Tamagusuku for technical assistance, and José Luis Leone and Fernando Corbella for critical reading of the manuscript.

Authors' affiliations

R J Viotti ${ }^{*}$, C Vigliano, S Laucella, B Lococo, M Petti, G Bertocchi, B Ruiz

Vera, H Armenti, Cardiology Department, Hospital Eva Perón, San Martin, Buenos Aires, Argentina

*Also Clinica Bessone, San Miguel, Buenos Aires, Argentina

\section{REFERENCES}

1 Feldman AM, Mac Namara D. Myocarditis. N Engl J Med 2000;343:1388-98

2 Anon. Tropical disease research progress 1975-1994 highlights 1993-1994. Twelfth programme report of the UNDP/World Bank/WHO Special Programme for Research and Training in Tropical Diseases (TDR). Geneva: World Health Organization, 1995:125-34.

3 Elizari M. La miocardiopatía chagásica: perspectiva histórica. Medicina 1999;59(suppl II):25-40

4 Yoshida N, Schenkman S. American trypanosomiasis. Curr Opin Infect Dis 1997; 10:351-6.

5 Jones EM, Colley DG, Tostes S, et al. Amplification of a Trypanosoma cruzi DNA sequence of inflammatory lesions in human chagasic cardiomyopathy. Am J Trop Med Hyg 1993;48:348-57.

6 Brandariz S, Schijman A, Vigliano C, et al. Detection of parasite DNA in Chagas' heart disease. Lancet 1995;346:1370.

7 Ouaissi A, Da Silva A, Guevara A, et al. Trypanosoma cruzi-induced host immune system dysfunction: a rationale for parasite immunosuppressive factor(s) encoding gene targeting. J Biomed Biotechnol 2001;1:11-7.

8 Tarleton RL, Zhang L. Chagas disease etiology: autoimmunity or parasite persistence? Parasitol Today 1999;15:94-9.

9 Andrade ZA. Immunopathology of Chagas disease. Mem Inst Oswaldo Cruzi 1999;94(suppl I):71-80.

10 Laranja F, Dias E, Nobrega G, et al. Chagas disease: a clinical, epidemiologic and pathologic study. Circulation 1956;14:1035-60.

11 Puigbó J, Giordano H, Suárez C, et al. Aspectos clínicos en la enfermedad de Chagas. In: Madoery R, Madoery C, Cámera M, eds. Actualizaciones en la enfermedad de Chagas. Simposio satélite. Organismo oficial del Congreso Nacional de Medicina. 1993:27-38.

12 Manzullo EC, Chuit R. Risk of death due to chronic chagasic cardiopathy Mem Inst Oswaldo Cruz 1999;94(suppl 1):317-20.

13 Storino R. Chagas crónico. In: Storino R, Milei J, eds. Enfermedad de Chagas. Buenos Aires: Mosby, 1994:249-54. 
14 Espinosa R, Carrasco HA, Belandria $F$, et al. Life expectancy analysis in patients with Chagas disease: prognosis after one decade. Int J Cardiol 1985;8:45-56.

15 Espinosa RA, Pericchi LR, Carrasco HA, et al. Prognostic indicators of chronic chagasic cardiopathy. Int J Cardiol 1991;30:195-202.

16 Bestetti RB, Dalbo CM, Freitas OC, et al. Non-invasive predictors of mortality for patients with Chagas heart disease: a multivariate stepwise logistic regression study. Cardiology 1994;84:261-7.

17 Rodriguez-Salas LA, Klein E, Acquatella $\mathrm{H}$, et al. Echocardiographic and clinical predictors of mortality in chronic Chagas' disease. Echocardiography 1998;15:271-8.

18 De Almeida Filho OC, Maciel BC, Schmidt A, et al. Minor segmental dyssynergy reflects extensive myocardial damage and global left ventricle dysfunc tion in chronic Chagas disease. J Am Soc Echocardiogr 2002;15:602-16.

19 Barros MV, Rocha MO, Ribeiro AL, et al. Doppler tissue imaging to evaluate early myocardium damage in patients with undetermined form of Chagas' disease and normal echocardiogram. Echocardiography 2001;18:131-6.

20 Salomone OA, Caeiro T. Regional changes of ventricular motility in patients with positive serology for Chagas disease. Medicina 1996;56:690-8.

21 Viotti R, Vigliano C, Armenti H, et al. Treatment of chronic Chagas' disease with benznidazole: clinical and serologic evolution of patients with long-term follow-up. Am Heart J 1994;127:151-62.

22 Kuschnir E, Sgammini H, Castro R, et al. Valoración de la función cardíaca por angiografía radioisotópica, en pacientes con cardiopatía chagásica crónica. Arq Bras Cardiol 1985;45:249-56.
23 Feigenbaum $\mathbf{H}$. Echocardiographic evaluation of cardiac chambers. In: Feigenbaum H, ed. Echocardiography, 5th edn. Philadelphia: Lea \& Febiger, 1994:147-9.

24 Bestetti RB. Role of apical aneurysm on the prognosis of chronic Chagas disease. Am J Cardiol 1998;82:1561.

25 Modena MG, Muia N, Sgura FA, et al. Left atrial size is the major predictor of cardiac death and overall clinical outcome in patients with dilated cardiomyopathy: a long-term follow-up study. Clin Cardiol 1997;20:553-60.

26 Higuchi ML, De Morais CF, Pereira Barreto AC, et al. The role of active myocarditis in the development of heart failure in chronic Chagas' disease: a study based on endomyocardial biopsies. Clin Cardiol 1987; 10:665-70.

27 Elizari MV, Chiale PA. Cardiac arrhythmias in Chagas heart disease. J Cardiovasc Electrophysiol 1993:4:596-608.

28 Acquatella $\mathrm{H}$, Schiller N, Puigbo J, et al. M-mode and two dimensional echocardiography in chronic Chagas heart disease: a clinical and pathologic study. Circulation 1980;62:787-99.

29 Medina N, Carrasco H, Fuenmayor A, et al. Diagnosis by non-invasive methods of incipient left ventricular lesions in patients with Chagas' disease. Use of echocardiographic and mechanocardiography. Arch Inst Cardiol Mex 1980;50:663-9.

30 Rigou DG, Gullone N, Carnevali L, et al. Asymptomatic Chagas disease: electrocardiographic and echocardiographic findings. Medicina $2001 ; 61: 541-4$.

\section{IMAGES IN CARDIOLOGY}

\section{Aneurysm of the left main coronary artery in Takayasu arteritis}

doi: $10.1136 /$ hrt.2003.023655

A 30 year old women was admitted to our hospital for evaluation of syncope. Her blood pressure was 100/ $70 \mathrm{~mm} \mathrm{Hg}$ in the left arm, while it was not recordable in the right arm. Systolic bruit was present over the right supraclavicular region. There was a blowing diastolic murmur over the left sternal border. ECG was normal. Laboratory studies gave either negative or normal results. There was no evidence of systemic inflammation. Erythrocyte sedimentation rate was normal, $\mathrm{C}$ reactive protein was negative, and blood counts were normal. Additionally rheumatoid factor and ANA were negative. She underwent angiographic evaluation with provisional diagnosis of Takayasu arteritis (TA). Aortogram revealed mild aortic regurgitation, total occlusion of the right subclavian artery, narrowing of the proximal left subclavian artery (below, left panel), and stenosis of the supra renal aorta (middle panel) consistent with a diagnosis of TA. Coronary angiogram showed a large aneurysm of the left main coronary artery (right panel).

Most of the discrete coronary artery aneurysms are atherosclerotic in origin; other causes of coronary aneurysms include Kawasaki disease, Takayasu disease, polyarteritis nodosa, and systemic lupus erythematosis. TA

is a chronic inflammatory vasculitis characterised by stenosis or obliteration of large and medium sized arteries. Morbidity results from arterial stenosis and organ ischaemia as well as from aneurysm formation. The cardiac sequelae of TA are far more commonly due to aortic regurgitation and inadequately treated hypertension than arteritis affecting the coronary vessels. Coronary arteries are affected in approximately $10 \%$ of the cases. Most of the lesions cause luminal narrowing; however, coronary aneurysm formation is extremely rare. The left main coronary artery is the least frequently involved artery. Aneurysm formation results from extensive destruction of elastic fibres in the media of the involved arterial wall as well as from arterial hypertension. A coronary aneurysm often causes stasis of blood flow and results in mural thrombus and myocardial infarction; saccular aneurysm may get thrombosed, ruptured or enlarged, resulting in myocardial infarction, cardiac tamponade or sudden death.

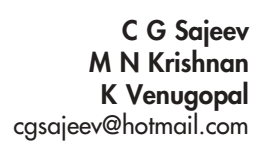

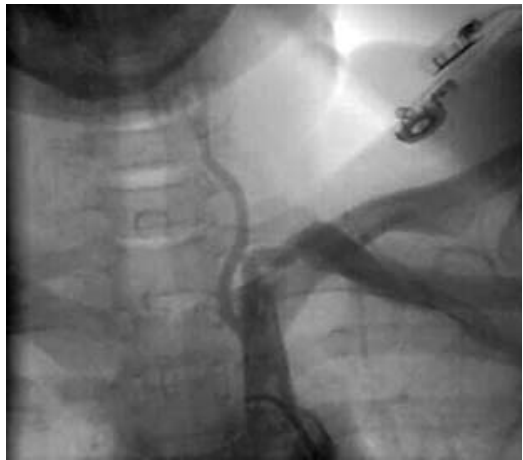

Left subclavian angiogram showing the characteristic narrowing in the subclavian artery.

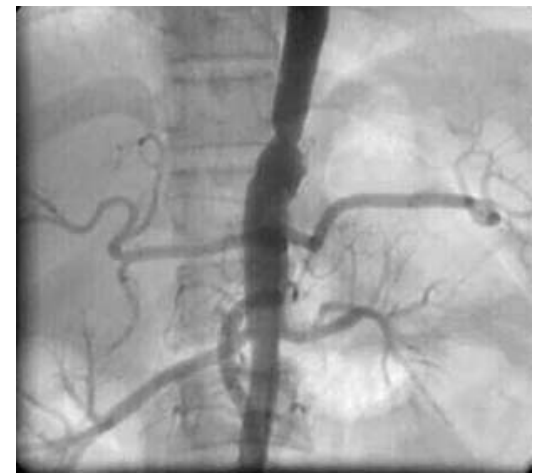

Aortogram showing narrowing of the supra renal aorta.

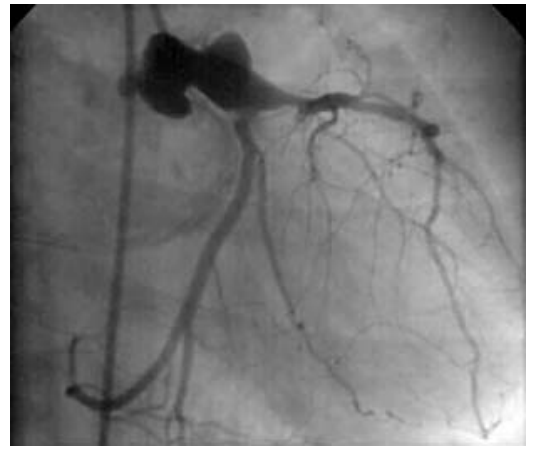

Coronary angiogram in the right anterior oblique showing aneurysm of the left main coronary artery. 